\title{
Quantifying scattered sound energy from a single tree by means of reverberation time
}

\author{
Hong-Seok Yang, Jian Kang ${ }^{*}$, Chris Cheal \\ School of Architecture, University of Sheffield, Western Bank, Sheffield, S10 2TN, UK
}

Timothy Van Renterghem, Dick Botteldooren

Department of Information Technology, Ghent University, Sint-Pietersnieuwstraat 41, B-9000 Gent, Belgium

${ }^{*}$ Contact details of the corresponding author:

Professor Jian Kang, School of Architecture, University of Sheffield, Western Bank, Sheffield S10 2TN, UK.

Tel: +44 114222 0325; Fax: +44 114222 0315; Email: j.kang@sheffield.ac.uk 


\section{ABSTRACT}

2 Trees in urban spaces surrounded by buildings may be effective in dispersing sound energy, 3 and this could affect sound level distribution and street canyon reverberation. To quantify this 4 effect of trees with a view to including it in numerical predictions, this paper examines sound 5 scattering from a single tree in open field by means of reverberation time (RT). Five trees of 6 different species and crown sizes were considered. The influence of ground condition, receiv-

7 er height, crown size and shape, foliage condition, and source-receiver angle and distance has 8 been assessed. The results show that RT20 is proportional to the tree crown size, which is the 9 most important factor. The maximum RT20 measured was $0.28 \mathrm{sec}$ at $4000 \mathrm{~Hz}$ for the studied trees when in leaf (with foliage). The presence of leaves increased RT20 at high frequencies, typically by $0.08 \mathrm{sec}$ at $4000 \mathrm{~Hz}$. It was also demonstrated that the source-receiver angle can affect the characteristics of decay curves significantly. With increasing source-receiver distance within $40 \mathrm{~m}$, RT20 was slightly changed. It was shown that ground condition and receiver height affect the decay curves, especially at low and mid frequencies, where sound scattering is of relatively limited importance. 


\section{I. INTRODUCTION}

2 In the last few decades since the pioneering work by Eyring ${ }^{1}$ in 1946, studies on the acoustic

3 effect of trees have been focused on sound propagation through forests and tree belts. A

4 number of studies have demonstrated the effect of forests and tree belts on noise reduction ${ }^{2-7}$.

5 Various numerical and experimental methods have also been investigated to characterize the

6 influential factors affecting sound propagation through forests. Previous work suggests that

7 ground effect, sound scattering, and sound absorption by tree elements (trunks, branches,

8 stems, leaves, etc.) play a significant role in sound propagation through forests ${ }^{8-21}$. Ground

9 effect is the result of interference between direct sound and sound reflected from the ground.

10 It depends on the acoustic properties of the ground, as well as the positions of the source and

11 receiver. At frequencies above $1 \mathrm{kHz}$, trees contribute to sound attenuation increasingly with

12 frequency due to sound scattering by trunks and branches, as well as foliage scattering and

13 absorption by viscous friction and damped vibrations. There have also been a few attempts to

14 show that forests induce a reverberant sound field, indicating the importance of sound scatter-

15 ing by tree elements ${ }^{22-24}$.

16 While there have been numerous studies involving groups of trees, it is also worth examining sound scattering by a single tree. Firstly, this helps validate theoretical models for predicting sound propagation through forests. Secondly, in reverberant urban spaces such as street canyons and courtyards, trees are expected to influence sound field characteristics including RT (reverberation time) and sound level distribution. Compared to open field, the effect of trees could even be enhanced since there are multiple passages through the trees due to multiple reflections between building façades ${ }^{25-27}$. Thus, information on sound scattering from a single tree would be useful for better understanding acoustic effects of trees in these urban environments. 
1 The aim of this study is therefore to investigate the effect of a single tree in open field on

2 sound scattering by means of RT, and to examine which parameters are relevant. The effect

3 of a single tree on sound scattering is expected to depend on many factors such as the tree

4 canopy size and species, the amount and seasonal condition of foliage, source-receiver angle

5 and distance, ground condition, and source and receiver heights. Consequently, a series of

6 field measurements involving five single trees of different species and crown sizes were car-

7 ried out.

\section{PRINCIPLE OF QUANTIFYING SCATTERED SOUND ENERGY FROM A SIN-}

\section{GLE TREE BY MEANS OF REVERBERATION TIME}

As shown in Fig. 1, sound propagating near a single tree can arrive at a receiver by a number of paths, including direct sound, ground reflected, purely scattered, and scattered in combination with ground reflection. This shows complex mechanisms of sound scattering produced by a single tree.

Fig. 2 shows two impulse responses measured in open field in the presence and absence of a single tree (Tree 5 in Fig. 3). The measurement was carried out at a source-receiver distance of $60 \mathrm{~m}$ for a point source (starting pistol) at $1.5 \mathrm{~m}$ height and a receiver at $1.5 \mathrm{~m}$ height. The result with the tree has considerably stronger sound energy in the late part of the impulse response in comparison with the result without the tree. Correspondingly, this would bring an increase in RT.

\section{MEASUREMENT METHOD}

\section{A. Experimental conditions}

Measurements were carried out six times in the Park at Chatsworth House near Sheffield, United Kingdom, between September 2010 and March 2012. Five individual trees of different species and sizes were selected to examine the importance of sound scattering (see Fig. 3). 
1 To suppress late reflections, the selected trees stood alone on flat grassland with sufficiently

2 large distances (over $70 \mathrm{~m}$ ) to other trees and obstacles. The sound scattered by a targeted

3 tree decays $35 \mathrm{~dB}$ from the initial amplitude within $150 \mathrm{~ms}$, or $51 \mathrm{~m}$ assuming a sound speed

4 of $340 \mathrm{~m} / \mathrm{s}$. Therefore, a maximum source-receiver distance of $60 \mathrm{~m}$ was determined to pro-

5 vide a sufficient time interval between scattered sound from a tree and late reflections from

6 other obstacles.

7 Table I describes properties of the five individual trees named from Tree 1 to Tree 5 on the 8 basis of increasing size. The areas of imaginary surfaces enclosing the tree crowns, with their 9 complex shapes, were calculated using Google's SketchUp programme with a function to 10 adjust scale on the basis of a reference object (i.e. a human figure in this study). Table II pro-

11 vides meteorological conditions during the measurements. Humidity and temperature were 12 measured $1.5 \mathrm{~m}$ above the ground with a CEM DT-615 meter just before and after each set of 13 acoustical measurements. Wind speed $2.5 \mathrm{~m}$ above the ground was recorded with a Testo $14 \quad 405-\mathrm{V} 1$ meter at the same times. Temperatures and relative humidity levels were quite similar 15 during the measurements, except on Days 2 and 6. This inconsistency might have caused different atmospheric absorption especially at high frequencies due to the rather long travelling

17 path in a tree crown. However, the atmospheric attenuation coefficient $\alpha(\mathrm{dB} / \mathrm{m})$ at $4000 \mathrm{~Hz}$ 18 for each measurement day, calculated based on ISO $9613-1^{28}$, indicates that the difference in

19 temperature and humidity has a negligible contribution to the variation in scattered sound for 20 the considered distances. The wind speed was less than $4 \mathrm{~m} / \mathrm{s}$, implying low background 21 noise by wind and the rustling of leaves. This has been confirmed by checking INR (impulseto-noise ratio). In Fig. 3, the condition for each tree with foliage is shown.

\section{B. Measurement setup}

24 A similar measurement methodology was used as reported before in the work by Ding et al. ${ }^{29}$ 
1 Shots from a starting pistol were used as acoustic excitation. Five consecutive shots were

2 released and the results averaged out, yielding a sufficient reproducibility for this type of

3 sound source $^{30}$. The recording systems comprised 1/2" microphones (BSWA MP 231 and

4 G.R.A.S. MCE 201) and preamplifiers (BSWA MA231T and 01dB-Stell Pre 12H) connected

5 respectively to a 4-channel Edirol R-44 recorder and a 2-channel 01dB Symphonie unit.

6 Sampling frequency and bit depth for both systems were $48 \mathrm{kHz}$ and 24-bit.

7 Fig. 4 shows the cross-section and top-view of the measurement condition, where the

8 source and receiver distance from a tree trunk is represented as $d_{s}$ and $d_{r}$, respectively,

9 while $h_{s}$ and $h_{r}$ are the heights of the sound source and receiver. The source-receiver

10 angle is defined with $\theta_{\mathrm{s}-\mathrm{r}}$, indicating the difference in angle between $\mathrm{d}_{\mathrm{s}}$ and $\mathrm{d}_{\mathrm{r}}$. Therefore,

$11 \theta_{\mathrm{s}-\mathrm{r}}=180$ degrees means a straight sound propagation path connecting source, trunk and

12 receiver.

\section{VALIDATION OF MEASUREMENT AND DATA ANALYSIS METHODS}

\section{A. Data analysis method}

In this study, RT based on the impulse responses recorded from the field measurement was analyzed using the DIRAC programme from $\mathrm{B} \& \mathrm{~K}^{31}$. RT is derived from the decay curve between $5 \mathrm{~dB}$ and 15, 25, $35 \mathrm{~dB}$ below the initial level. From the corresponding slope, T10, $\mathrm{T} 20$ and $\mathrm{T} 30$ are calculated as the times to reach $-60 \mathrm{~dB}$ relative to the initial level. EDT (ear-

19 ly decay time), derived from the decay curve between $0 \mathrm{~dB}$ and $10 \mathrm{~dB}$ below the initial level, is an inadequate descriptor to evaluate the scattered sound from trees as there is relatively weak energy in comparison with a direct sound. DIRAC has the time reversed filtering function to enable accurate measurement of very short RT which is needed for this study.

\section{B. Impulse response to noise ratio}

The INR is an important parameter, providing information about the quality of the measure- 
ment for RT. It is defined as the ratio of the maximum impulse response level and background noise level, reflecting the decay range. According to ISO $3382-2^{32}$, the INR should be at least $35 \mathrm{~dB}$ and $45 \mathrm{~dB}$ for accurate measurement of T20 and T30, respectively.

At the source-receiver distance of $60 \mathrm{~m}\left(\mathrm{~d}_{\mathrm{r}}=30 \mathrm{~m}, \mathrm{~d}_{\mathrm{s}}=30 \mathrm{~m}, \theta_{\mathrm{s}-\mathrm{r}}=180\right.$ degrees $)$, the INR measured for Tree 2 on Day 3 was $22.2 \pm 2.2 \mathrm{~dB}$ at $63 \mathrm{~Hz}, 36.8 \pm 2.8 \mathrm{~dB}$ at $125 \mathrm{~Hz}, 45.0 \pm 2.7 \mathrm{~dB}$ at $250 \mathrm{~Hz}, 48.8 \pm 2.5 \mathrm{~dB}$ at $500 \mathrm{~Hz}, 48.4 \pm 2.9 \mathrm{~dB}$ at $1000 \mathrm{~Hz}, 56.6 \pm 1.5 \mathrm{~dB}$ at $2000 \mathrm{~Hz}$ and $54.0 \pm 2.5 \mathrm{~dB}$ at $4000 \mathrm{~Hz}$. The standard deviation indicates the variation in the INR for five consecutive pistol shots. The maximum standard deviation of $2.9 \mathrm{~dB}$ at $1000 \mathrm{~Hz}$ suggests that the measurement method using starting pistol shots is reliable. The result suggests that the INR is sufficiently high to calculate T10 and T20 for source-receiver distances within $60 \mathrm{~m}$, which is the maximum source-receiver distance considered in this study. However, it can be seen that the INR at some frequencies including $63 \mathrm{~Hz}, 125 \mathrm{~Hz}$ and $250 \mathrm{~Hz}$ is insufficient to calculate T30. Therefore, it is appropriate to use T10 or T20 in terms of data reliability although the INR at $63 \mathrm{~Hz}$ is still insufficient for calculating T20.

\section{Determination of RT}

In Fig. 5, decay curves in octave band frequencies from $125 \mathrm{~Hz}$ to $4000 \mathrm{~Hz}$ are shown for sound propagating in the presence and absence of Tree 3 with foliage. In this measurement, the source and receiver were positioned at $d_{s}=10 \mathrm{~m}, \mathrm{~d}_{\mathrm{r}}=10 \mathrm{~m}, \mathrm{~h}_{\mathrm{r}}=0.2 \mathrm{~m}, \mathrm{~h}_{\mathrm{s}}=0.2$ $\mathrm{m}$ and $\theta_{\mathrm{s}-\mathrm{r}}=180$ degrees. The measurement without the tree was carried out at the same conditions, except with a slightly different source-receiver distance of $\mathrm{d}_{\mathrm{s}}=13 \mathrm{~m}$ and $\mathrm{d}_{\mathrm{r}}=13 \mathrm{~m}$ which has a negligible contribution to the variation in RT. The result for open field without the tree indicates that RT at low frequency is rather long, mainly because of the filters applied during the post-processing of the time responses. This cannot be avoided, and thus some ghost RT that has no physical meaning will always be measured 
1 at very low frequencies. However, the filter effect induces negligible ghost RT for T10

2 and T20 less than $0.02 \mathrm{sec}$. On the other hand, decay curves in the presence of Tree 3

3 show that above $1000 \mathrm{~Hz}$, trees clearly introduce reverberation. It is also noticeable that

4 weak scattering sound at $500 \mathrm{~Hz}$ is produced after $-25 \mathrm{~dB}$ below the initial level, which

5 can cause significant variation in RT with different decay ranges, especially for T30.

6 Fig. 6 shows RT with the three different decay ranges for the decay curves in Fig. 5. The

7 standard deviation in Fig. 6 indicates the variation in RT for five consecutive pistol

8 shots. The result for the presence of Tree 3 shows that RT generally increases with in-

9 creasing frequency. This corresponds with prior knowledge that sound energy is more

10 effectively scattered by vegetation and trees at high frequencies than at low frequencies,

11 yet RT remains less than $0.2 \mathrm{sec}$. It is noticeable that $\mathrm{T} 30$ at $500 \mathrm{~Hz}$ is considerably dif-

12 ferent from T10 and T20 due to weak scattering of the direct sound but relatively im-

13 portant sound levels arriving after $10 \mathrm{~ms}$. RT measured in open field suggests that the

14 DIRAC programme is accurate for calculating impulse responses with very short RT

15 although T30 is slightly longer compared to T10 and T20. It is also noted that RT at low

16 frequencies is not caused by the tree because the results with and without the single tree

17 are similar. In this study, therefore, the decay range for T20 is used to investigate the

18 sound scattering effect of a single tree.

\section{Repeatability of the measurement method}

20 Repeatability of the measurement method was examined on Day 3 and Day 4, with a 12 day

21 interval. The temperature and humidity on both days were rather similar, as can be seen in

22 Table II. The measurement was carried out for Tree 2 with foliage at the source-receiver dis-

23 tance of $20 \mathrm{~m}\left(\mathrm{~d}_{\mathrm{r}}=10 \mathrm{~m}, \mathrm{~d}_{\mathrm{s}}=10 \mathrm{~m}\right)$. The measurement condition for source and receiver was

$24 \mathrm{~h}_{\mathrm{r}}=0.2 \mathrm{~m}, \mathrm{~h}_{\mathrm{s}}=0.2 \mathrm{~m}$ and $\theta_{\mathrm{s}-\mathrm{r}}=180$ degrees. It was estimated that the maximum difference in 
1 RT20 between the two days is $0.03 \mathrm{sec}$ at $500 \mathrm{~Hz}$, which indicates the repeatability of the

2 measurement and analysis methods.

3 To examine uniformity of sound scattering, RT20 for the six straight lines $\left(\theta_{\mathrm{s}-\mathrm{r}}=180\right.$ degrees $)$

4 with 60 degrees interval, meaning one rotation in reference to the tree trunk, was measured

5 for Tree 2 with foliage. The source-receiver distance and height were the same as described

6 above. The maximum difference in RT20 between the results measured at the six different

7 straight lines positions was $0.02 \mathrm{sec}$. Thus, Tree 2 can be considered as a uniform scatterer in

8 the horizontal plane. It is expected that other trees could also scatter sound uniformly as the

9 canopies are approximately symmetric.

10 E. Ground conditions and receiver heights

11 Differences in ground conditions can affect RT20 due to the variation in the amplitude of 12 reflected sound. Although field measurements were carried out at the same source and re13 ceiver configurations, the ground condition for each tree could be different due to many fac14 tors such as root structure, soil composition, moisture content, and seasonal influences.

15 Therefore, it is necessary to investigate the effect of ground condition on sound scattering.

16 For this, the decay curve for grassland (assumed as soft ground) is compared with that for 17 three different ground conditions using $2 \mathrm{~mm}$ thick hard plastic panels covering the sourcereceiver line from the tree trunk. The four different ground conditions were: (1) bare grassland all around the tree, (2) $11 \mathrm{~m}$ long by $2 \mathrm{~m}$ wide hard cover on the receiver $R$ side, (3) 11 m long by $2 \mathrm{~m}$ wide hard cover on the source $S$ side, (4) these hard covers on the $S$ and $R$ sides simultaneously. The measurement was conducted for Tree 2 on Day 6 with $\mathrm{d}_{\mathrm{r}}=10 \mathrm{~m}$, $\mathrm{d}_{\mathrm{s}}=10 \mathrm{~m}$ and $\theta_{\mathrm{s}-\mathrm{r}}=180$ degrees. The effect of receiver height on the decay curve was also examined at $h_{r}=0.2,1.5,3.0$ and $4.0 \mathrm{~m}$ with the same source height of $h_{s}=0.2 \mathrm{~m}$. In Fig. 7, decay curves with the different ground conditions at the receiver height of $0.2 \mathrm{~m}$ for Tree 2 are 
1 shown from $500 \mathrm{~Hz}$ to $4000 \mathrm{~Hz}$.

2 The result in Fig. 7 indicates that the different ground conditions play an important role in the

3 characteristics of the decay curves, especially at $500 \mathrm{~Hz}$ and $1000 \mathrm{~Hz}$. At $500 \mathrm{~Hz}$, in compari-

4 son with soft grassland, the amplitude near $10 \mathrm{~ms}$ with the hard ground on the receiver side is

5 rather high. At $1000 \mathrm{~Hz}$, relatively strong sound energy for soft ground near the receiver can

6 be found at rather late parts of decay curves in comparison with hard ground. At higher fre-

7 quencies, on the other hand, the variation in the characteristics of the decay curves with dif-

8 ferent ground conditions is insignificant. This is consistent with the fact that ground effects,

9 averaged over full-octave bands, are not present anymore ${ }^{33}$ at these frequency bands. Hard

10 ground on the source side seems to have less influence. This lack of reciprocity remains un-

11 explained.

12 Fig. 8 shows the effect of the ground conditions and receiver heights on RT20 for Tree 2. The 13 standard deviation again indicates the difference in RT20 for five consecutive pistol shots.

14 The result in Fig. 8 shows that the different ground conditions produce variations in RT20 at

15 all receiver heights, especially at $500 \mathrm{~Hz}$ and $1000 \mathrm{~Hz}$ for the considered source-receiver ge-

16 ometry, while there is an insignificant difference in RT20 at lower and higher frequencies.

17 The results also show that receiver heights can affect the variation in RT20 at certain fre18 quencies.

\section{MEASUREMENT RESULTS}

\section{A. Effects of tree size with and without foliage}

21 The trees considered in this study have five different heights between $7.7 \mathrm{~m}$ and $20.6 \mathrm{~m}$. The

22 diameters of the five tree crowns are between $6.9 \mathrm{~m}$ and $21.5 \mathrm{~m}$. To examine the effect of tree

23 crown size on scattered sound energy, measurements were carried out with a source-receiver

24 distance of $20 \mathrm{~m}\left(\mathrm{~d}_{\mathrm{r}}=10 \mathrm{~m}, \mathrm{~d}_{\mathrm{s}}=10 \mathrm{~m}\right)$ and $\theta_{\mathrm{s}-\mathrm{r}}=180$ degrees for the five trees with and without 
1 foliage. The height of both source and receiver was $0.2 \mathrm{~m}$. The measurements for the five

2 trees with and without foliage were carried out on Day 3 and Day 5, respectively. For the five

3 trees with foliage, Fig. 9 shows the decay curves in octave band frequencies from $500 \mathrm{~Hz}$ to

$44000 \mathrm{~Hz}$. Decay curves at low frequencies are not shown here because there is insignificant

$5 \quad$ sound scattering by the trees.

6 The result in Fig. 9 indicates that the RT20 proportionally increases with increasing size of

7 the trees because a larger tree produces relatively stronger sound scattering and longer sound

8 paths through the crown. Above $500 \mathrm{~Hz}$, it can be seen that the characteristics of decay

9 curves significantly depend on the tree size. For relatively small trees like Tree 1, Tree 2 and

10 Tree 3, the scattered sound energy at $500 \mathrm{~Hz}$ is weak relative to direct sound. The results at

11 high frequencies show that the slope of decay curves is rather linear with a slow decrease of

12 sound energy. The decay time at $4000 \mathrm{~Hz}$ for Tree 4 is approximately $120 \mathrm{~ms}$ at $-25 \mathrm{~dB}$ be-

13 low the initial level, indicating long travelling paths in the tree crown.

14 Fig. 10 shows RT20 according to the surface area of the trees with and without foliage in 15 octave band frequencies from $500 \mathrm{~Hz}$ to $4000 \mathrm{~Hz}$. Above $500 \mathrm{~Hz}$, RT20 is gradually in16 creased with the increasing surface area of the trees. The maximum RT20 is $0.26 \mathrm{sec}$ at 4000 $17 \mathrm{~Hz}$ for Tree 4 with foliage. It is noted that the RT20 at $4000 \mathrm{~Hz}$ is decreased above around $200 \mathrm{~m}^{2}$. This was because a large number of leaves on Tree 5 were fallen on Day 3 due to the season, as shown in Fig. 3. However, the result from another measurement, obtained on Day

20 1, indicates that RT20 at $4000 \mathrm{~Hz}$ can reach $0.28 \mathrm{sec}$ when Tree 5 is in full leaf. It can also be 21 seen that single trees without foliage can contribute to the increase in RT20 with increasing tree crown size. Compared to the trees with foliage, RT20 for the relatively small trees (Tree 1, Tree 2 and Tree 3) without foliage is higher at $500 \mathrm{~Hz}$ and $1000 \mathrm{~Hz}$ due to different ground conditions between Day 3 and Day 5. Since the sound source is low $\left(\mathrm{h}_{\mathrm{s}}=0.2 \mathrm{~m}\right)$, interference 
1 patterns only appear for relatively high frequencies, i.e. above $500 \mathrm{~Hz}$. Thus, this leads to

2 some important uncertainties in the analysis of the effect of trees without and with foliage

3 due to different ground conditions.

4 The leaves on the five single trees studied here have widths and lengths below $15 \mathrm{~cm}$. This

5 size corresponds to the wavelength of sound at $2250 \mathrm{~Hz}$, and thus it is expected that foliage

6 has an influence mainly on sound scattering at or above this frequency. At $4000 \mathrm{~Hz}$, it is

7 shown that RT20 for trees with foliage is higher than those without foliage. In particular,

8 RT20 by Tree 4 is increased by $0.08 \mathrm{sec}$ in the presence of foliage, confirming that foliage

9 scattering occurs at high frequencies. As for Tree 5, RT20 at $4000 \mathrm{~Hz}$ can be increased by

$100.08 \mathrm{sec}$ when in full leaf. Overall, the results indicate that leaves increase RT20 at high fre-

11 quencies. The size and thickness of leaves as well as LAI (Leaf Area Index) and LAD (Leaf

12 Area Density) could also play a role, but this was not studied here.

\section{B. Source-receiver angle}

14 The characteristics of decay curves are influenced by source-receiver angle ( $\left.\theta_{\mathrm{s}-\mathrm{r}}\right)$ (see Fig. 4).

15 In this study, the effect of source-receiver angle on the decay curve is examined using Tree 2

16 without foliage on Day 2. The measurement condition was $d_{s}=13 \mathrm{~m}, \mathrm{~d}_{\mathrm{r}}=13 \mathrm{~m}, \mathrm{~h}_{\mathrm{s}}=1.5 \mathrm{~m}$ and

$17 \mathrm{~h}_{\mathrm{r}}=1.5 \mathrm{~m}$. The source-receiver angles were $0,90,135$ and 180 degrees. The source-receiver angle of 0 degrees was used to estimate the back scattered sound energy (or reflection), which was measured with $d_{s}=40 \mathrm{~m}$ and $d_{r}=10 \mathrm{~m}$ arranged in a line without the tree between the source and receiver.

In Fig. 11, the decay curves for Tree 2 without foliage with different source-receiver angles are shown at different frequencies. The result shows that decay curves for the source-receiver angle of 135 degrees (45 degrees in reference to 180 degrees) is similar to that for 180 de- 
1 both source-receiver angles due to the relatively close receiver distance from the edge of the

2 tree crown. For the source-receiver angle of 90 degrees, there is a plateau between direct and

3 scattered sound with the time interval of approximately $15 \mathrm{~ms}(5.1 \mathrm{~m}$ for a speed of sound of

$4 \quad 340 \mathrm{~m} / \mathrm{s})$. This is caused by the difference in distance for the direct sound path (18.4 m) with

5 scattered sound paths $(21.5 \mathrm{~m} \sim 26.0 \mathrm{~m})$ from the edge of the crown and the trunk. The decay

6 curve for the source-receiver angle of 0 degrees (back scattering) suggests that the tree can

7 reflect sound energy backwards effectively. It can be seen that there is a pronounced plateau

8 with the time interval of approximately $50 \mathrm{~ms}(17.0 \mathrm{~m})$ between direct and reflected sound,

9 which indicates strong reflection from the vicinity of the tree trunk. The relative SPL vs time

10 in Fig. 11 suggests that Tree 2 without foliage can reflect sound at frequencies above $250 \mathrm{~Hz}$.

11 In summary, the source-receiver angle can affect characteristics of the decay curve signifi-

12 cantly, especially for 0 degrees and 90 degrees. Calculation of RT20 is omitted here due to

13 the long time interval between direct and reflected sound.

\section{C. Source-receiver distance}

15 Measurements for the five individual trees with foliage on Day 3 were conducted to investi16 gate the effect of source-receiver distance on RT20. Values for $d_{s}$ (source-trunk distance) were $10 \mathrm{~m}$, and for $\mathrm{d}_{\mathrm{r}}$ (receiver-trunk distance) 5, 10, 20 and $30 \mathrm{~m}$. The source, tree and receiver were arranged in a straight line with $\theta_{\mathrm{s}-\mathrm{r}}=180$ degrees. Therefore, the range of sourcereceiver distances was between $15 \mathrm{~m}$ and $40 \mathrm{~m}$. The height of the source and receiver was 0.2 m. Fig. 12 presents RT20 measured with $d_{s}=10 \mathrm{~m}$ for different frequencies as a function of $\mathrm{d}_{\mathrm{r}}=5,10,20,30 \mathrm{~m}$. At $125 \mathrm{~Hz}$ and $250 \mathrm{~Hz}, \mathrm{RT} 20$ is under $0.03 \mathrm{sec}$ and independent of source-receiver distance. It can be seen that the source-receiver distance plays an insignificant role on RT20 above $500 \mathrm{~Hz}$, except in the case of Tree 5. The variation in RT20 for Tree 5 might be due to the relatively thick trunk and low leaf density, and measurement locations 
1 slightly deviating from the straight line between source and receiver. Therefore, it can be

2 concluded that the different source-receiver distances studied here have an insignificant effect

3 on the variation in RT20.

\section{VI. DISCUSSION AND CONCLUSIONS}

5 This study has shown that sound scattering is a significant aspect of the interaction between

6 sound waves and trees. This effect is quantified by means of decay curves, closely linked to

7 the RT, as influenced by the ground condition, receiver heights, tree crown shape and size,

8 the amount and condition of foliage, and source-receiver angle and distance. Repeatability for

9 the measurement using a starting pistol has also been confirmed.

10 The results quantify the amount of scattered sound energy from a single tree at different fre-

11 quencies. At very low frequencies, below $250 \mathrm{~Hz}$, no difference in RT20 has been found compared to the same measurement setup and post-processing in absence of a tree (open field). At higher frequencies, the amount of scattered sound energy is generally increased with increasing frequency. It has been found that tree crown size is the most important factor in relation to scattering of sound energy. With increasing surface area of the crown (area of an enclosing surface), RT20 is increased up to $0.28 \mathrm{sec}$ at $4000 \mathrm{~Hz}$. A tree without foliage also produces a similar amount of scattered sound energy as a tree with foliage. Presence of leaves increases RT20 starting from $2000 \mathrm{~Hz}$, by $0.08 \mathrm{sec}$ at $4000 \mathrm{~Hz}$. The characteristics of decay curves are significantly influenced by source-receiver angle, especially for 0 and 90 degrees. Back scattering (or reflection) from a tree has also been observed at frequencies above $250 \mathrm{~Hz}$. It has been observed that distance between source and receiver (within $40 \mathrm{~m}$ ) under the same angle has insignificant effect on the variation in RT20. Ground condition can contribute to the variation in decay and RT20 at certain frequencies depending on the tree size and source-receiver geometry. However, for the source-receiver geometry of this study 
1 the effect is important especially at low and mid frequencies where sound scattering is of

2 relatively limited importance.

3 Although many field measurements have been carried out in this study, further work is still

4 needed to characterize the effect of other factors such as leaf size, leaf shape and thickness,

5 but also the distribution of biomass over the crown, quantified by LAD (Leaf Area Density).

6 Numerical modeling of scattering of sound energy by trees (as initiated e.g. in Refs. 7 and 34),

7 as well as scale modeling could further clarify the physical phenomena involved and allow

8 evaluation of potential applications. A previous study ${ }^{35}$ showed only a slight effect (less than

$9 \quad 1.5 \mathrm{~dB}$ ) on sound reduction by the presence of trees in street canyons. On the other hand,

10 trees in street canyons could be significant in RT distribution since a slight increase in the

11 scattering coefficient of building façades reduces street canyon reverberation, as shown in

12 previous studies ${ }^{36-39}$. Thus, it is necessary to suggest effective planting patterns of trees in

13 urban situations to reduce noise levels. Optimization of planting schemes was shown to be

14 essential, e.g. in the context of tree belts (see Ref. 7), to achieve useful noise reduction.

\section{ACKNOWLEDGEMENTS}

17 The research leading to these results has received funding from the European Community's 18 Seventh Framework Programme (FP7/2007-2013) under grant agreement $n^{\circ} 234306$, collabo19 rative project HOSANNA. This research was also supported by Korea NRF (No. 201120 0007171), China NSF (50928801), PRC MoE Foundation for PhD (20112302110045), 21 Helongjian Province Fund (LC2009C22), and Harbin TIF (2012RFXXS046). The authors are indebted to Dr. Yuliya Smyrnova for useful discussion. 


\section{REFERENCES}

[1] C. F. Eyring, “Jungle Acoustics,” J. Acoust. Soc. Am. 18, 257-270 (1946).

[2] T. F. W. Embleton, "Sound propagation in homogeneous deciduous and evergreen wood s,” J. Acoust. Soc. Am. 35, 1119-1125 (1963).

[3] J. Kragh, "Road traffic noise attenuation by belts of trees," J. Sound Vib. 74, 235-241 (19 $81)$.

[4] F. Fricke, "Sound attenuation in forests," J. Sound Vib. 92, 149-158 (1984).

[5] C. F. Fang and D. L. Ling, "Investigation of the noise reduction provided by tree belts," Landscape Urban Plan. 63, 187-195 (2003).

[6] V. Tyagi, K. Kumar and V. K. Jain, "A study of the spectral characteristics of traffic noise attenuation by vegetation belts in Delhi," Appl. Acoust. 67, 926-935 (2006).

[7] T. Van Renterghem, D. Botteldooren and K. Verheyen, "Road traffic noise shielding by v egetation belts of limited depth,” J. Sound Vib. 331, 2404-2425 (2012).

[8] D. Aylor, "Sound transmission through vegetation in relation to leaf area density, leaf wid th, and breadth of canopy," J. Acoust. Soc. Am. 51, 411-414 (1972).

[9] S. H. Burns, "The absorption of sound by pine trees," J. Acoust. Soc. Am. 65, 658-661 (1 979).

[10] M. J. M. Martens, "Foliage as a low-pass filter - experiments with model forests in an anechoic chamber," J. Acoust. Soc. Am. 67, 66-72 (1980).

[11] M. J. M. Martens and A. Michelsen, "Absorption of acoustic energy by plant leaves," J. Acoust. Soc. Am. 69, 303-306 (1981).

[12] M. A. Price, K. Attenborough and N. W. Heap, "Sound attenuation through trees: mea surements and models," J. Acoust. Soc. Am. 84, 1836-1844 (1988).

[13] T. Watanabe and S. Yamada, "Sound attenuation through absorption by vegetation," J. Acoust. Soc. Jpn. 17, 175-182 (1996).

[14] T. Van Renterghem and D. Botteldooren, "Effect of a row of trees behind noise barrier s in wind," Acta Acust. United Ac. 88, 869-878 (2002).

[15] D. Heimann, "Numerical simulations of wind and sound propagation through an ideali sed stand of trees," Acta Acust. United Ac. 89, 779-788 (2003).

[16] R. Martínez-Sala, C. Rubio, L. M. García-Raffi, J. V. Sánchez-Pérez, E. A. Sánchez-P érez and J. Llinares, "Control of noise by trees arranged like sonic crystals," J. Sound Vib. 291, 100-106 (2006).

[17] M. E. Swearingen and M. J. White, "Influence of scattering, atmospheric refraction, a 
nd ground effect on sound propagation through a pine forest," J. Acoust. Soc. Am. 122, 1 13-119 (2007).

[18] T. Van Renterghem and D. Botteldooren, "Numerical evaluation of tree canopy shape near noise barriers to improve downwind shielding," J. Acoust. Soc. Am. 123, 648-657 (2 008).

[19] J. M. Wunderli and E. M. Salomons, "A model to predict the sound reflection from fore sts," Acta Acust. United Ac. 95, 76-85 (2009).

[20] Y. Fan, B. Zhiyi, Z. Zhujun and L. Jiani, "The investigation of noise attenuation by plan ts and the corresponding noise-reducing spectrum," J. Environ. Health 72, 8-15 (2010).

[21] J. M. Wunderli, "An extended model to predict reflections from forests," Acta Acust. U nited Ac. 98, 263-278 (2012).

[22] D. G. Richards and R. H. Wiley, "Reverberations and amplitude fluctuations in the prop agation of sound in a forest: implications for animal communication,” Amer. Nat. 115, 3 81-399 (1980).

[23] W. H. T. Huisman and K. Attenborough, "Reverberation and attenuation in a pine fores t,” J. Acoust. Soc. Am. 90, 2664-2677 (1991).

[24] M. Padgham, "Reverberation and frequency attenuation in forests - implications for aco ustic communication in animals," J. Acoust. Soc. Am. 115, 402-410 (2004).

[25] J. Kang, "Sound propagation in street canyons: Comparison between diffusely and geo metrically reflecting boundaries," J. Acoust. Soc. Am. 107, 1394-1404 (2000).

[26] J. Kang, "Numerical modelling of the sound fields in urban squares," J. Acoust. Soc. A m. 117, 3695-3706 (2005).

[27] T. Van Renterghem, E. Salomons and D. Botteldooren, "Parameter study of sound prop agation between city canyons with a coupled FDTD-PE model," Appl. Acoust. 67, 487510 (2006).

[28] ISO 9613-1 (1993) Acoustics - Attenuation of sound during propagation outdoors Part 1: Calculation of the absorption of sound by the atmosphere (International Organiz ation for Standardization, 1993).

[29] L. Ding, T. Van Renterghem and D. Botteldooren, "Measurement methodology for the acoustic scattering of a single tree," Proceedings of the 20th international congress on acoustics (ICA 2010), Sydney, Australia.

[30] T. Van Renterghem and D. Botteldooren, "In-situ measurements of sound propagating over extensive green roofs," Build. Environ. 46, 729-738 (2011). 
1 [31] DIRAC v5. User's manual; 2010.

2 [32] ISO 3382-2 (2008) Acoustics - Measurement of room acoustic parameters - Part 2: Rev 3 erberation time in ordinary rooms (International Organization for Standardization, 4 2008).

5 [33] ISO 9613-2 (1996) Acoustics - Attenuation of sound during propagation outdoors 6 Part 2: General method of calculation (International Organization for Standardization, 1996).

8 [34] M. Hornikx, D. Botteldooren, T. Van Renterghem, J. Forssen, "Modelling of scattering of sound from trees by the PSTD method," Proceedings of Forum Acusticum 2011, Aal borg, Denmark.

[35] Z. Haron, K. Yahya, R. Zakaria and D. Oldham, "Modeling of sound propagation in urb an streets containing trees using Markovian technique," Malaysian Journal of Civil Eng ineering 21, 55-68 (2009).

[36] J. Kang, "Numerical modelling of the sound fields in urban streets with diffusely reflect ing boundaries," J. Sound Vib. 258, 793-813 (2002).

[37] J. Kang, Acoustics of Long Spaces: theory and design guidance (Thomas Telfor d, London, 2002).

[38] J. Kang, Urban sound environment (Taylor and Francis, London, 2007).

[39] H. Onaga and J. H. Rindel, "Acoustic characteristics of urban streets in relation to scattering caused by building facades," Appl. Acoust. 68, 310-325 (2007). 


\section{$1 \quad$ List of Tables}

2

3 TABLE I. Dimensional properties of the trees

4 TABLE II. Meteorological conditions for each measurement day 5

6

7

8

9

10

11

12

13

14

15

16

17

18

19

20

21

22

23

24

25

26

27

28

29 
TABLE I. Dimensional properties of the trees

\begin{tabular}{|c|c|c|c|c|c|}
\hline & Tree 1 & Tree 2 & Tree 3 & Tree 4 5 \\
\hline Species & $\begin{array}{c}\text { Oak } \\
\text { Q. robur })\end{array}$ & $\begin{array}{c}\text { Oak } \\
\text { (Q. petraea })\end{array}$ & $\begin{array}{c}\text { Cherry } \\
(\text { P. avium })\end{array}$ & $\begin{array}{c}\text { Maple } \\
\text { (A. pseudoplatanus) })\end{array}$ & $\begin{array}{c}\text { Lime } \\
(\text { T. } \times \text { europaea })\end{array}$ \\
\hline $\begin{array}{c}\text { Tree height } \\
(\mathrm{m})\end{array}$ & 7.7 & 9.2 & 11.5 & 14.9 & 20.6 \\
\hline $\begin{array}{c}\text { Tree crown diameter } \\
(\mathrm{m})\end{array}$ & 6.9 & 12.3 & 15.7 & 19.5 & 21.5 \\
\hline $\begin{array}{c}\text { Crown surface area } \\
(\text { enclosing surface }) \\
\left(\mathrm{m}^{2}\right)\end{array}$ & 30 & 43 & 88 & 161 & 218 \\
\hline $\begin{array}{c}\text { Leaf size } \\
(\mathrm{cm})\end{array}$ & $12.0(\mathrm{~L}) \times 7.5(\mathrm{~W})$ & $12.0(\mathrm{~L}) \times 7.5(\mathrm{~W})$ & $15.0(\mathrm{~L}) \times 6.0(\mathrm{~W})$ & $12.0(\mathrm{~L}) \times 15.0(\mathrm{~W})$ & $10.0(\mathrm{~L}) \times 10.0(\mathrm{~W})$ \\
\hline $\begin{array}{c}\text { Trunk diameter } \\
(\mathrm{m})\end{array}$ & 0.14 & 0.40 & 0.42 & 0.51 & 0.56 \\
\hline $\begin{array}{c}\text { Distance from } \\
\text { ground to bottom of } \\
\text { crown }(\mathrm{m})\end{array}$ & 1.9 & 1.8 & 1.9 & 2.0 & 2.0 \\
\hline
\end{tabular}

2

3

4

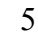

6

16

17 
1 TABLE II. Meteorological conditions for each measurement day

\begin{tabular}{|c|c|c|c|c|c|c|}
\hline & Day 1 & Day 2 & Day 3 & Day 4 & Day 5 & Day 6 \\
\hline Date & $21^{\text {st }}$ Sep.2010 & $20^{\text {th }}$ Apr.2011 & $14^{\text {th }}$ Oct.2011 & $26^{\text {th }}$ Oct.2011 & $13^{\text {th }}$ Mar.2012 & $14^{\text {th }}$ Mar. 2012 \\
\hline $\begin{array}{c}\text { Temperature } \\
\left({ }^{\circ} \mathrm{C}\right)\end{array}$ & 20.3 & 28.2 & 16.3 & 15.0 & 15.6 & 9.9 \\
\hline $\begin{array}{c}\text { Relative humidity } \\
(\%)\end{array}$ & 62.0 & 34.1 & 65.8 & 65.1 & 56.7 & 74.3 \\
\hline $\begin{array}{c}\text { Wind speed } \\
(\mathrm{m} / \mathrm{s})\end{array}$ & $<1.0$ & $<1.4$ & $<3.0$ & $<2.3$ & $<2.5$ & $<4.0$ \\
\hline $\begin{array}{c}\text { Atmospheric } \\
\text { attenuation coeffi- } \\
\text { cient } \alpha \text { at } 4000 \mathrm{~Hz} \\
(\mathrm{~dB} / \mathrm{m})\end{array}$ & 0.025 & 0.031 & 0.027 & 0.028 & 0.031 & 0.031 \\
\hline
\end{tabular}

2

3

4

5

6

7

8

9

10

11

12

13

14

15

16

17

18

19

20

21

22

23 


\section{$1 \quad$ List of Figures}

3 FIG. 1. Diagram for sound paths through a single tree from a point source to a receiver

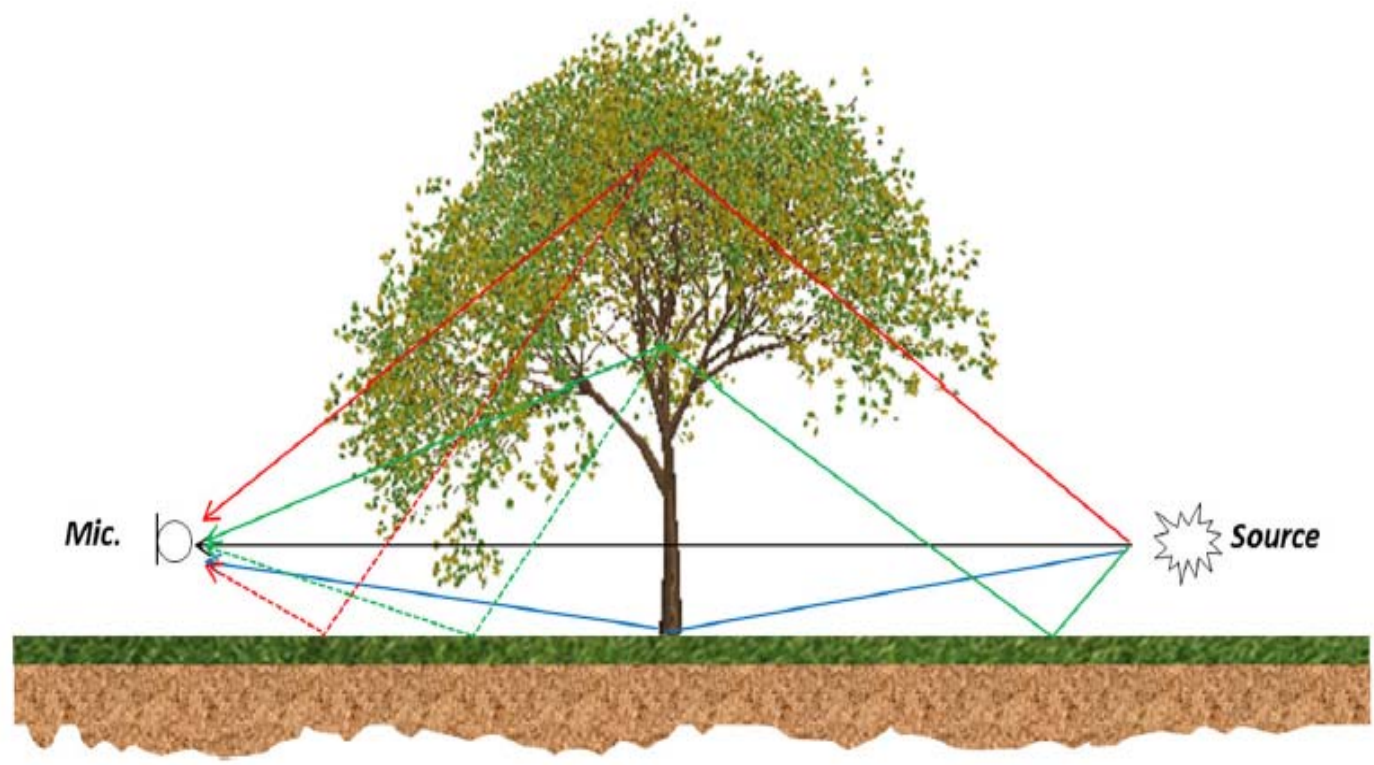

4

5 FIG. 2. Impulse responses measured in open field in the absence and presence of a single tree

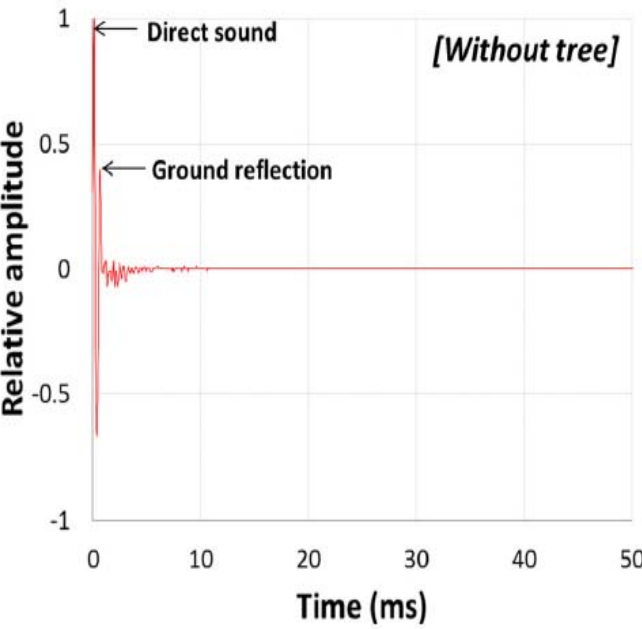

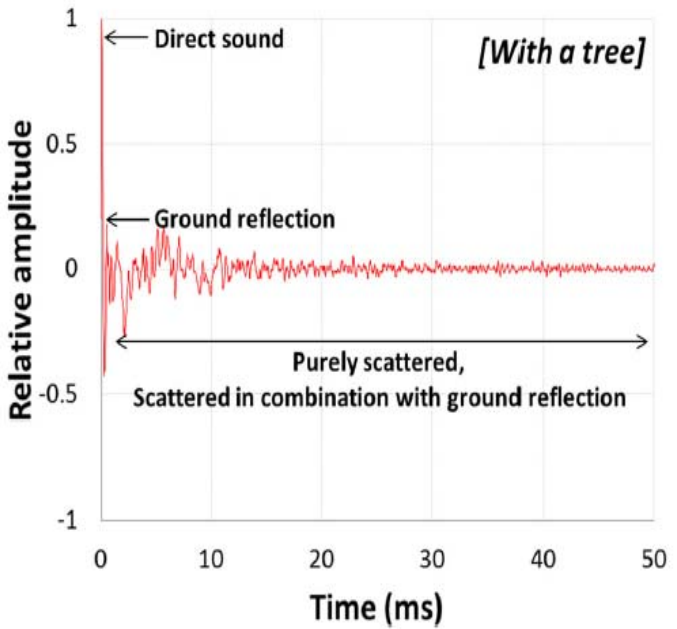

6

$7 \quad$ FIG. 3. Conditions for five trees with foliage on Day 3 

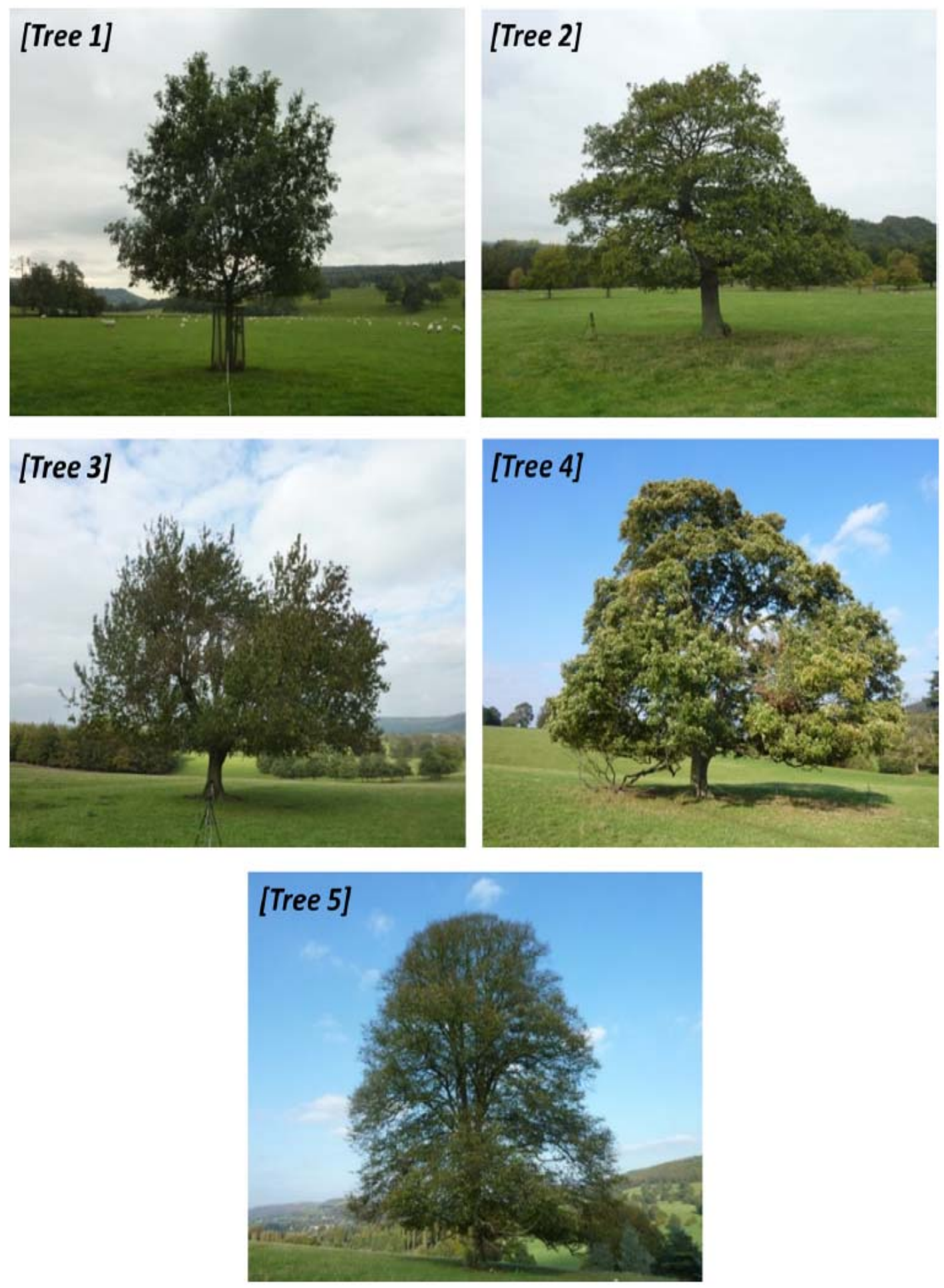

FIG. 4. Cross-section and top-view for measurement conditions, where $d_{r}$ is the trunk-receiver dis3 tance, $d_{s}$ is trunk-source distance, $h_{r}$ is the receiver height, and $h_{s}$ is the source height 

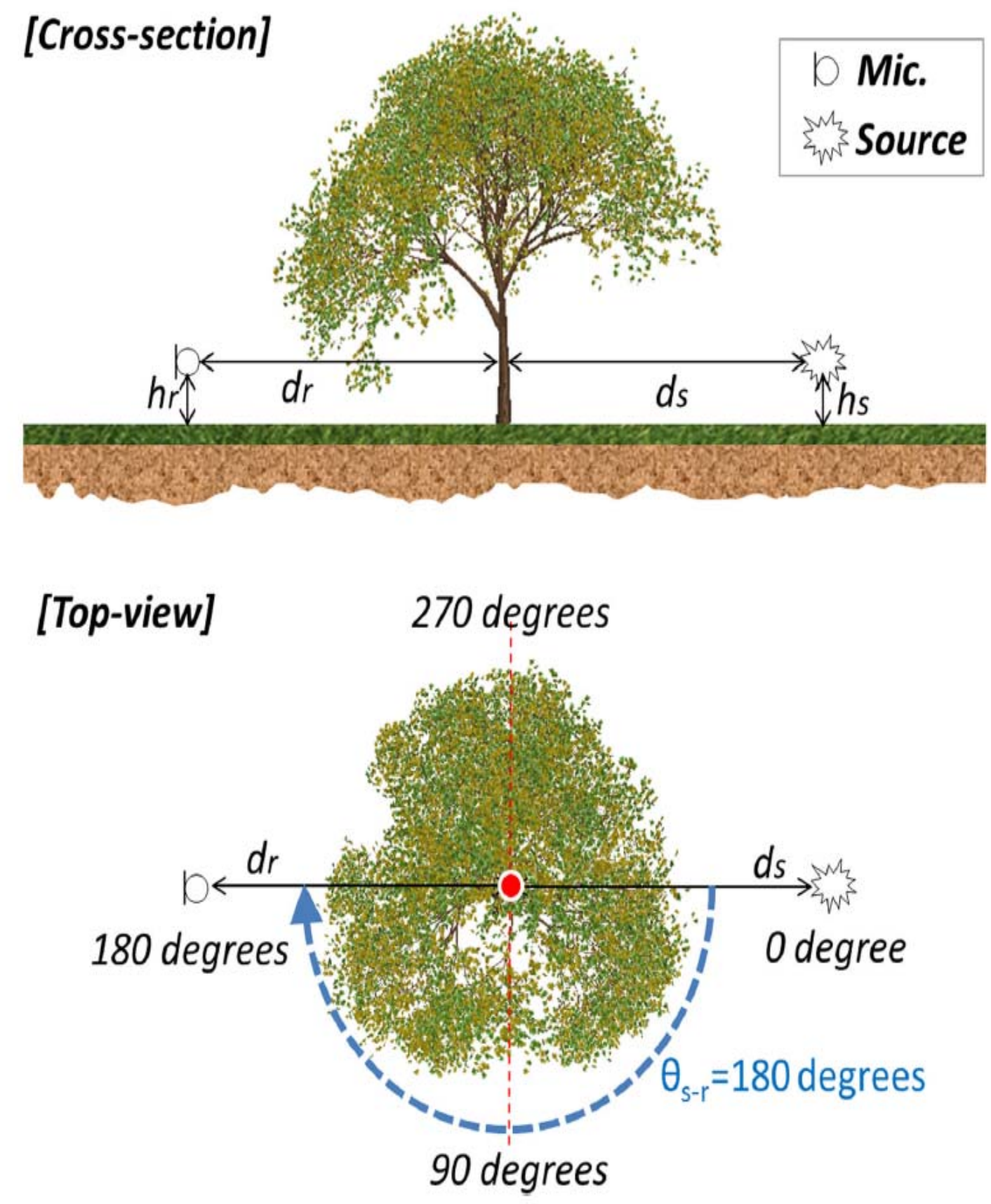

2 FIG. 5. Comparison of decay curves in the absence and presence of a single tree (Tree 3) 

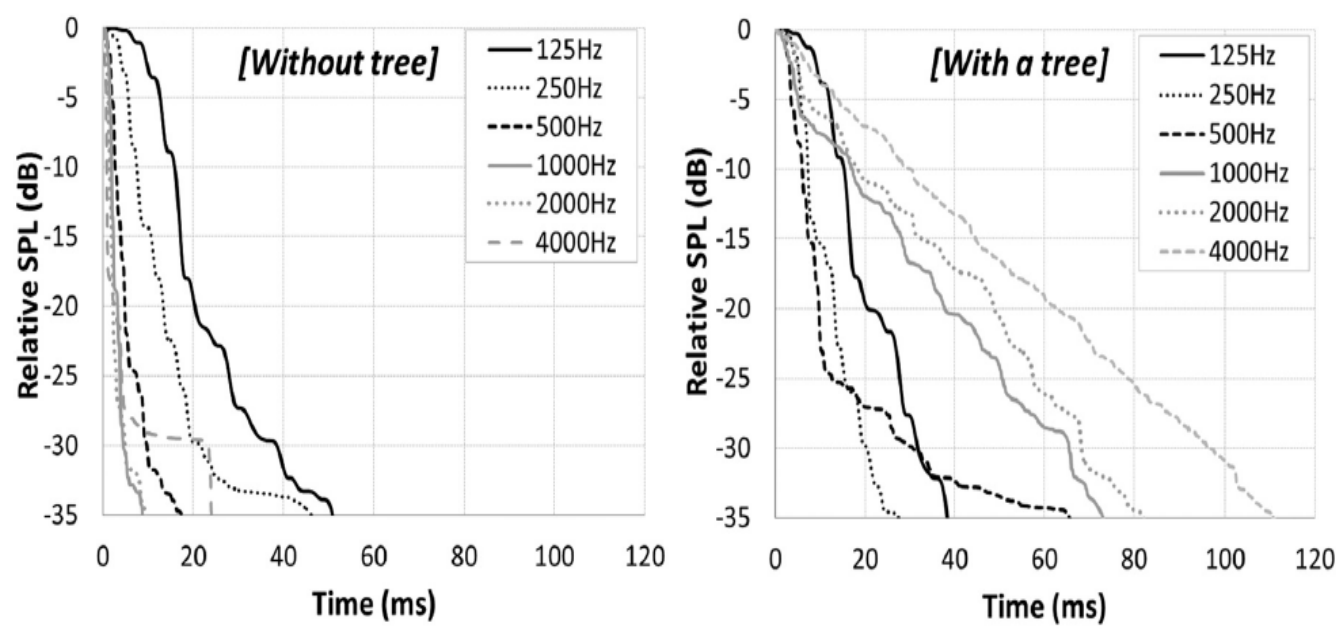

2 FIG. 6. RT with the three decay ranges corresponding to T10, T20 and T30 in the absence and pres3 ence of a single tree (Tree 3 )
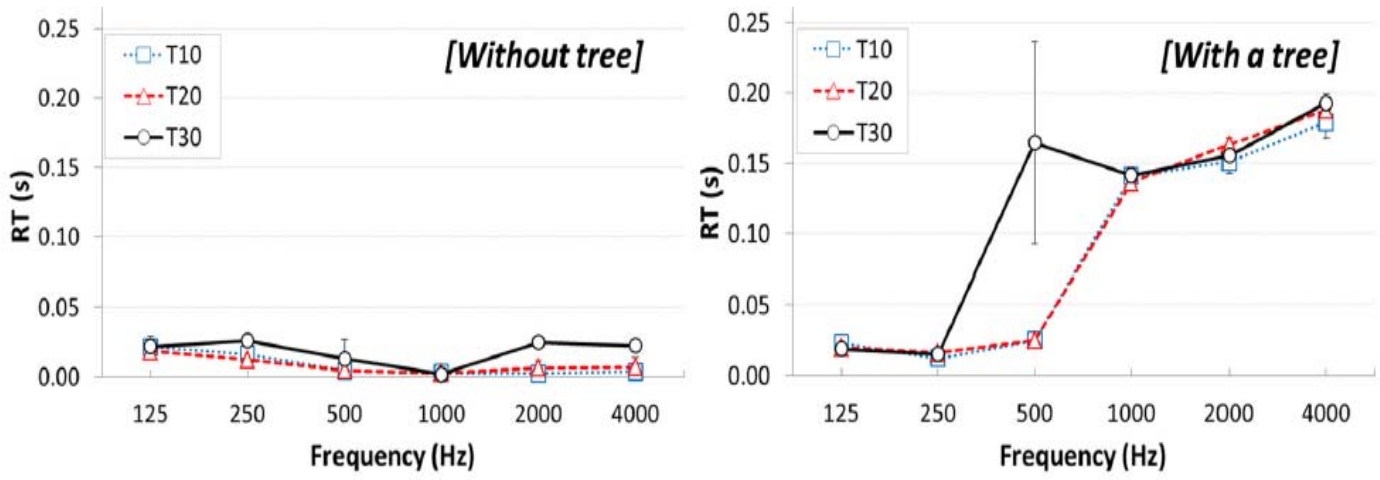

4

5 FIG. 7. Decay curves with the four different ground conditions at the receiver and source heights of $60.2 \mathrm{~m}$ for Tree 2. Each figure shows the decay curves in octave band frequencies from $500 \mathrm{~Hz}$ to 4000 $7 \mathrm{~Hz}$ 

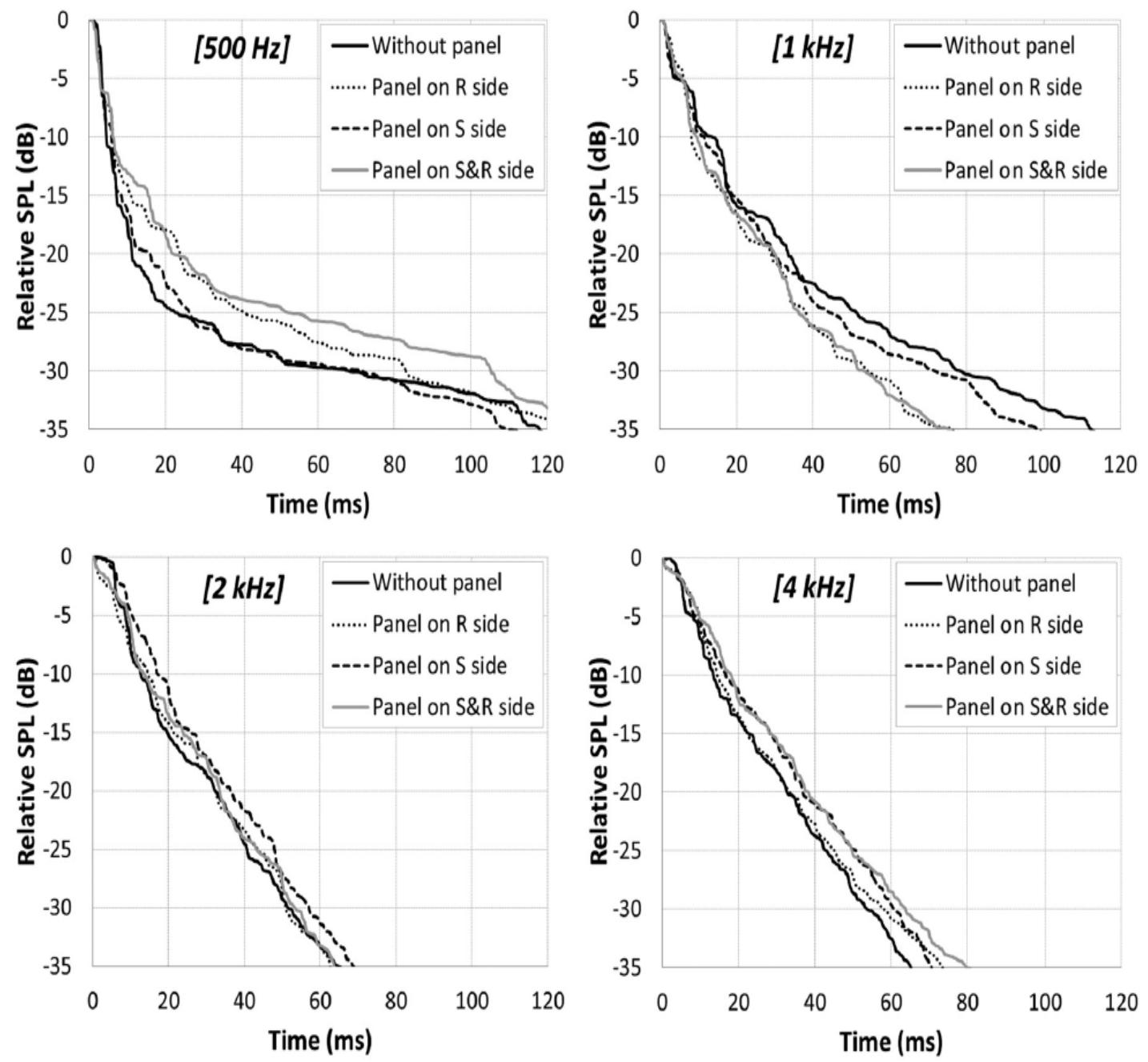

2 FIG. 8. Effect of the different ground conditions on RT20 for Tree 2 with different receiver heights 3 from $0.2 \mathrm{~m}$ to $4.0 \mathrm{~m}$ (source height $0.2 \mathrm{~m}$ ) 

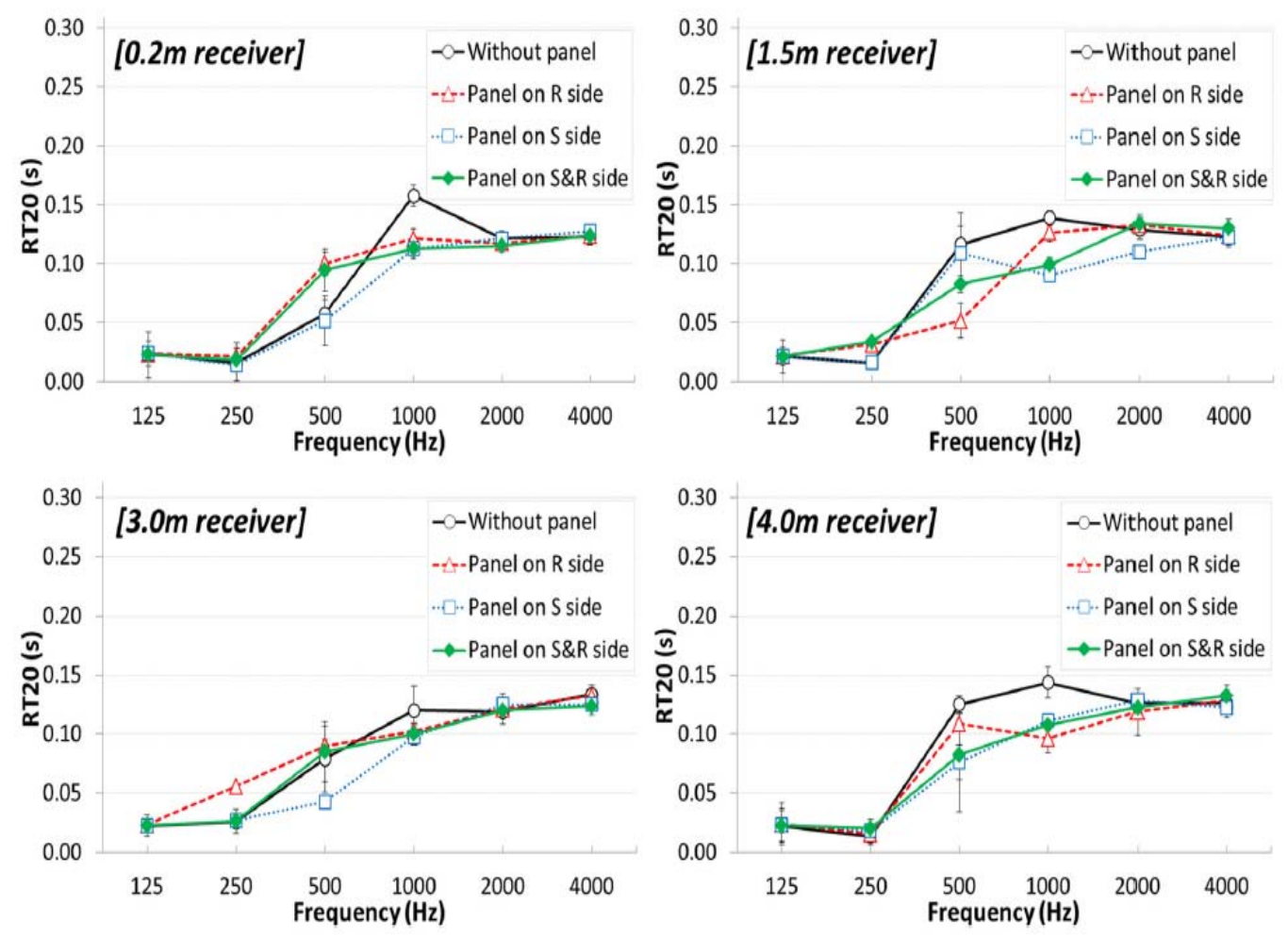

2 FIG. 9. Decay curves for the five trees with foliage. Each figure shows the decay curves in octave 3 band frequencies from $500 \mathrm{~Hz}$ to $4000 \mathrm{~Hz}$ 

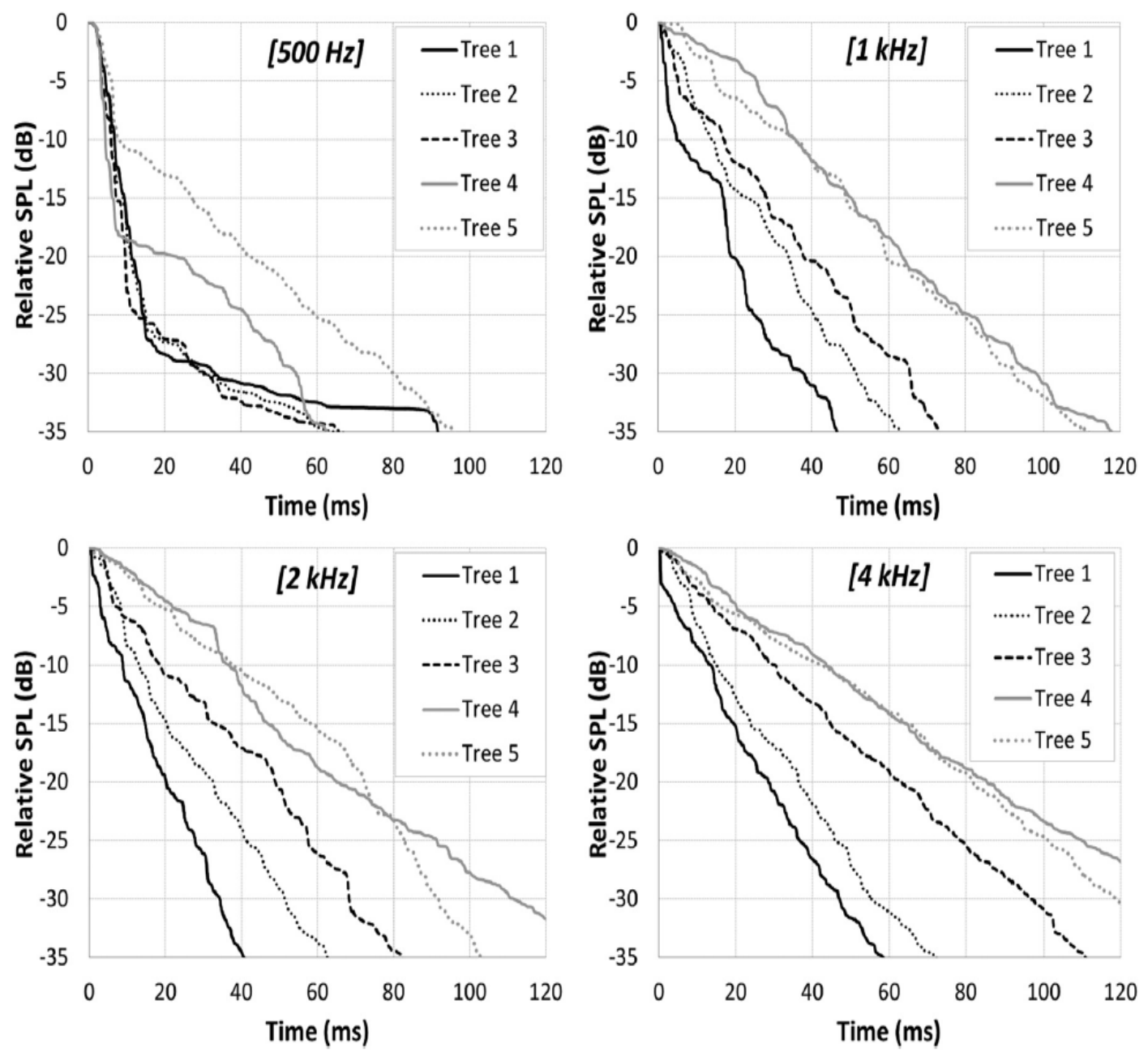

FIG. 10. Effect of the surface area of tree crown with and without foliage on RT20. Each figure shows

3 RT20 in octave band frequencies from $500 \mathrm{~Hz}$ to $4000 \mathrm{~Hz}$ 

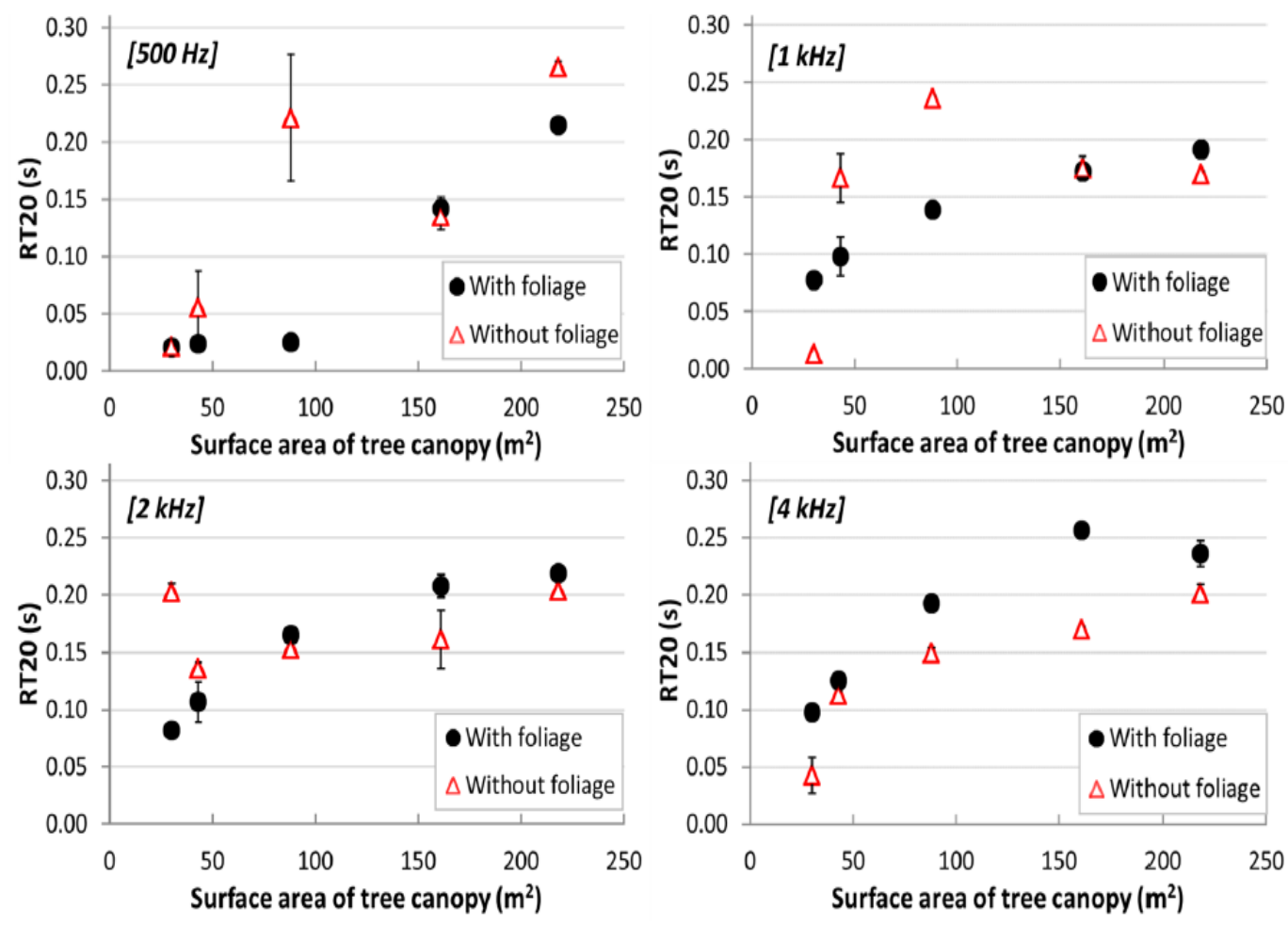

1

2 FIG. 11. Decay curves for Tree 2 without foliage with different source-receiver angles. Each figure 3 shows the decay curves in octave band frequencies from $125 \mathrm{~Hz}$ to $4000 \mathrm{~Hz}$ 

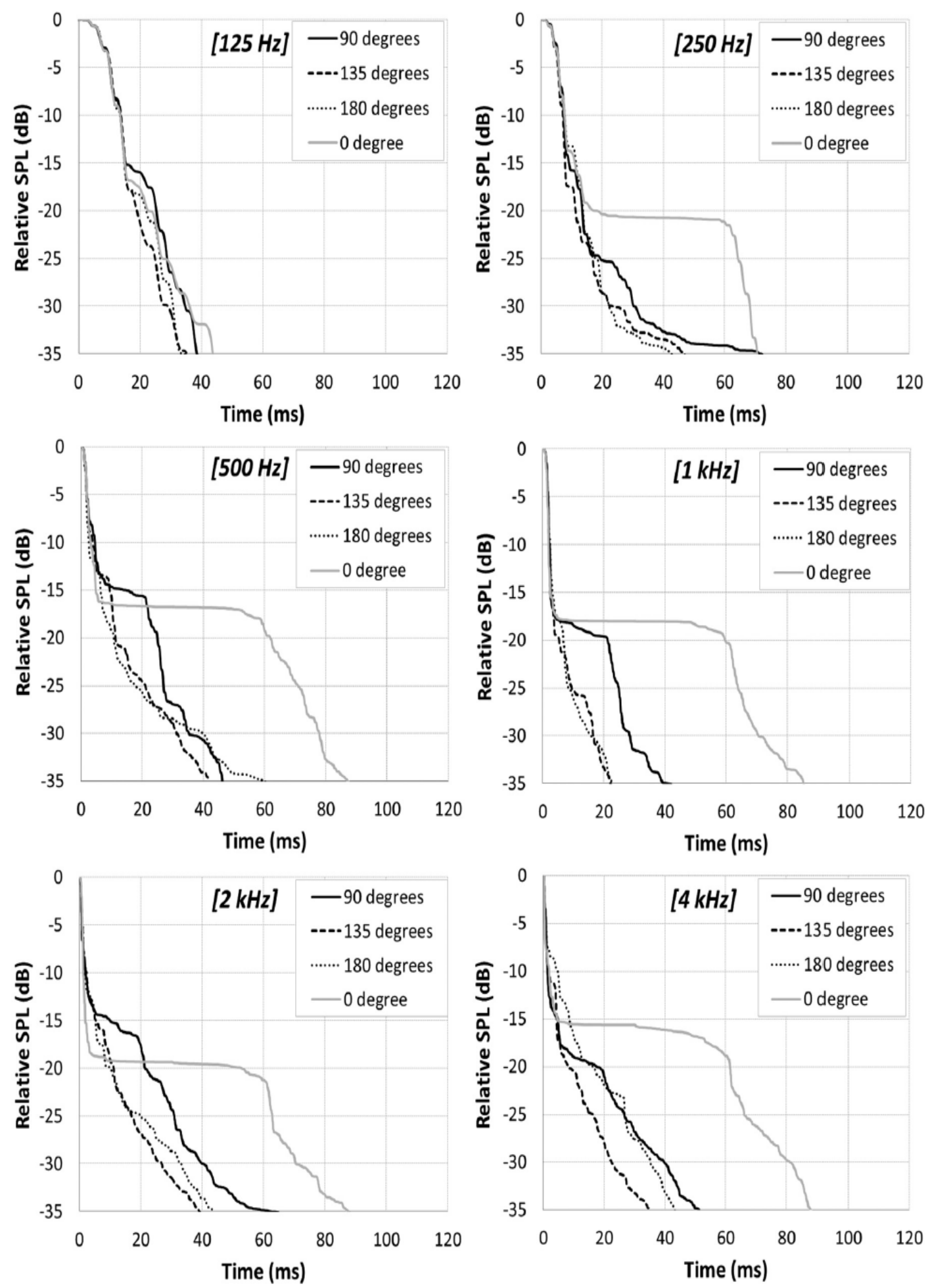

2 FIG. 12. RT20 with different source-receiver distances from $15 \mathrm{~m}$ to $40 \mathrm{~m}$, with $\mathrm{d}_{\mathrm{s}}=10 \mathrm{~m}$ and $\mathrm{d}_{\mathrm{r}}=5,10$, $320,30 \mathrm{~m}$ for each tree. Each figure shows the decay curves in octave band frequencies from $500 \mathrm{~Hz}$ to $4 \quad 4000 \mathrm{~Hz}$ 

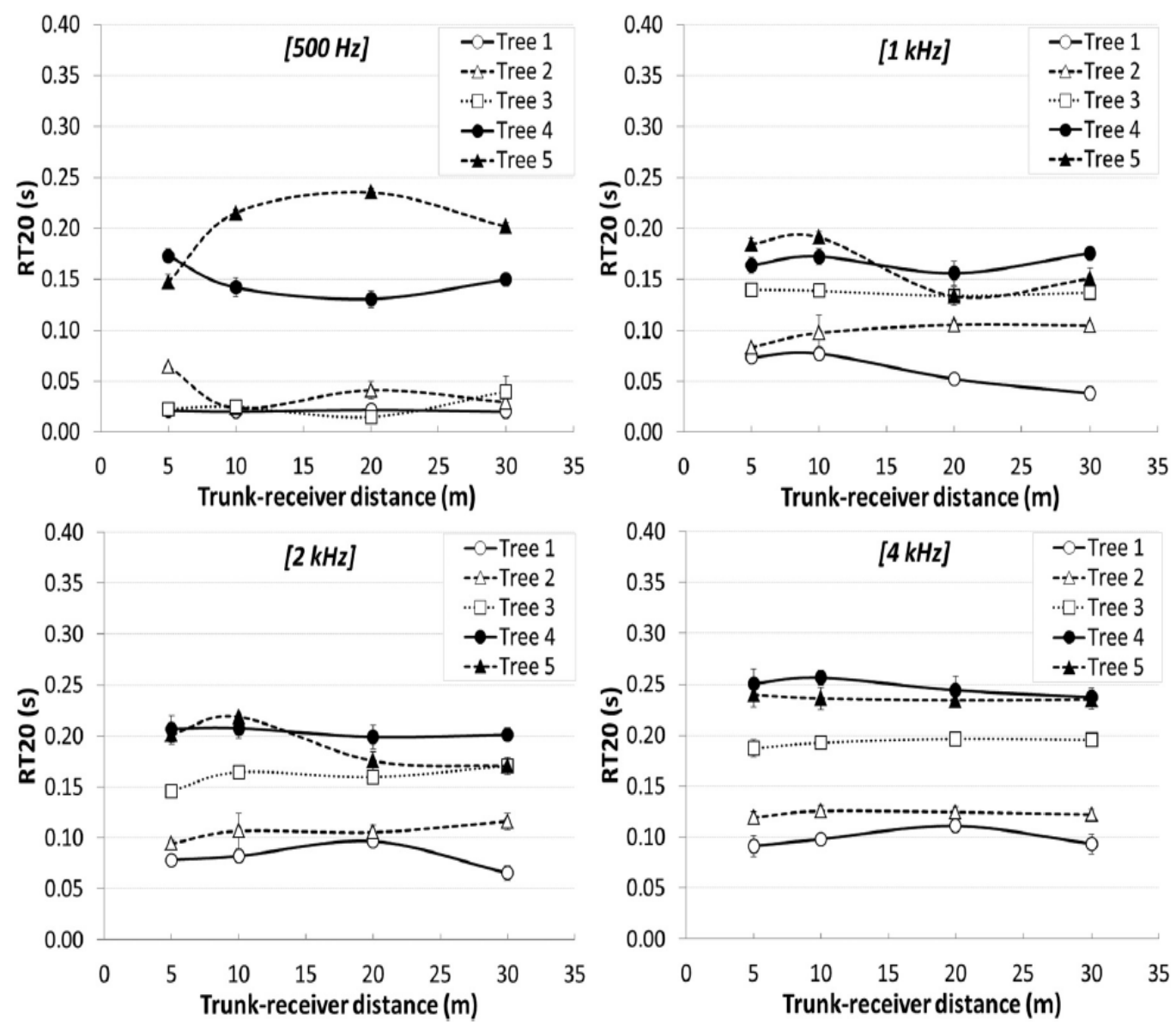